\title{
High frequency oscillatory ventilation
}

\author{
AC BRYAN MB PhD, D BOHN MB \\ Pediatric Intensive Care Unit, Hospital for Sick Children, University of Toronto, Toronto, Ontario
}

\section{AC BRYAN, D BOHN. High frequency oscillatory ventila-} tion. Can Respir J 1996;3(6):368-369.

High frequency oscillatory (HFO) ventilation using low tidal volume and peak airway pressures is extremely efficient at eliminating carbon dioxide and raising $\mathrm{pH}$ in the newborn infant with acute respiratory failure. Improvement in oxygenation requires a strategy of sustained or repetitive inflations to 25 to $30 \mathrm{~cm} \mathrm{H}_{2} \mathrm{O}$ in order to place the lung on the deflation limb of the pressure-volume curve. This strategy has also been shown to decrease the amount of secondary lung injury in animal models. Experience of the use of HFO ventilation as a rescue therapy as well as several published controlled trials have shown improved outcomes and a decrease in the use of extracorporeal membrane oxygenation when it has been used in newborns.

Key Words: High frequency oscillatory ventilation

\section{Ventilation oscillatoire à haute fréquence}

RÉSUMÉ : La ventilation oscillatoire à haute fréquence faisant appel à de faibles volumes courants et à une pression maximale à la bouche est très efficace pour éliminer le gaz carbonique et augmenter le $\mathrm{pH}$ chez le nouveau-né atteint d'une insuffisance respiratoire aiguë. L'amélioration de l'oxygénation nécessite une approche d'inflations soutenues ou répétées pour atteindre une

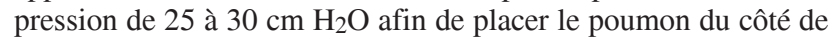
la phase de déflation de la courbe pression-volume. Il a été démontré que cette approche réduisait le nombre de traumatismes pulmonaires secondaires chez les modèles animaux. L'expérience de l'utilisation de la ventilation oscillatoire à haute fréquence comme thérapie de sauvetage de même que les résultats publiés d'essais comparatifs ont démontré une amélioration des résultats et une diminution de l'utilisation de l'oxygénation par membrane extracorporelle lorsqu'elle a été appliquée chez les nouveau-nés.
$\mathrm{T}$ here is abundant evidence that conventional mechanical ventilation in which high pressures are used, and particularly if little or no positive end-expiratory pressure (PEEP) is applied, can cause damage to normal lungs and amplify injury in abnormal lungs.

As a result the current recommendations in adults are to use low peak pressures, ie, less than $35 \mathrm{~cm} \mathrm{H}_{2} \mathrm{O}$, and a high PEEP, about 10 to $20 \mathrm{~cm} \mathrm{H}_{2} \mathrm{O}$. While this strategy appears to minimize lung injury and optimize oxygenation, the tidal volume (VT) is usually too low to eliminate carbon dioxide effectively. In adults this permissive hypercapnia is generally very well tolerated, although there is still argument about how low the $\mathrm{pH}$ should be allowed to go and whether buffers should be used (1). However, in the infant, because acidosis has a profound effect on the pulmonary vascular resistance (2), permissive hypercapnia is either contraindicated or, at best, a dubious strategy.

High frequency oscillation (HFO) offers an alternative because it can provide a low peak pressure, low VT and high PEEP strategy, and it gives excellent control of $\mathrm{PaCO}_{2}$. The chequered history of HFO has been the result of a failure to understand the principles behind this strategy. The purpose of this paper is to restate these principles.

\section{CARBON DIOXIDE ELIMINATION}

Initially the most surprising thing about HFO was its extraordinary ability to eliminate carbon dioxide because VT was considerably less than the anatomical dead space. Al-

Correspondence: Dr D Bohn, The Department of Critical Care Medicine, The Hospital for Sick Children, 555 University Avenue, Toronto, Ontario M5G 1X8. Telephone 416-813-6477, fax 416-813-7299, e-mail dbohn@ sickkids.on.ca 
though there is still no exact or singular explanation, a series of mixing phenomena can achieve the required alveolar ventilation (3). Carbon dioxide exchange is achieved approximately by the product of $\mathrm{VT}^{2}$ and frequency (f) (4); therefore there is no optimum VT or $\mathrm{f}$. If a low $\mathrm{f}$ is employed, the VT and, hence, the alveolar distension have to be increased, which is probably undesirable. Working at very high $\mathrm{f}$ is mechanically inefficient. In practice, we have generally used $\mathrm{f}$ of $15 \mathrm{HZ}$ because at a fixed $\mathrm{f}$ the chest wall motion is a useful clue to the adequacy of VT. Initially there was some concern that HFO could cause air trapping, which certainly was a considerable problem during high frequency jet ventilation. One oscillator (SensorMedics, Inc, California) provides a 1:3 inspiratory:expiratory (I:E) ratio; however, we have never experienced gas trapping, nor has it been reported in other oscillators using a 1:1 I:E ratio (5).

Given the linearity of the carbon dioxide dissociation curve in the physiological range, it follows that hyperventilation of relatively few alveoli will affect normal carbon dioxide exchange. HFO is therefore very effective in controlling carbon dioxide. The exceptions are when airways disease impedes the transmission of oscillations to the alveoli. Therefore, it is generally ineffective in meconium aspirations syndromes, bronchopulmonary dysplasia and bronchiolitis.

\section{OXYGENATION}

The fact that oscillation can remove carbon dioxide does not necessarily mean it can adequately oxygenate the blood. In the presence of shunt due to atelectatic or flooded alveoli, oscillations per se are useless. This situation requires high mean airway pressures to open and hold open these closed units. To achieve this, volume recruitment manoeuvres are necessary (6). These use either sustained or repetitive inflations to 25 to $30 \mathrm{~cm} \mathrm{H}_{2} \mathrm{O}$ to place the lung on the deflation limb of the pressure-volume curve. Following this, oscillation is continued at a mean airway pressure that in acute lung disease is usually between 10 and $20 \mathrm{~cm} \mathrm{H}_{2} \mathrm{O}$. HFO allows these high levels of mean airway pressure without the necessity for high peak pressures to get sufficient convective flow for carbon dioxide removal. The peak-to-peak pressures registered on the oscillator look very high, but the resistive

\section{REFERENCES}

1. Feihl F, Perret C. However permissive should we be. Am J Respir Crit Care Med 1994;150:1722-34.

2. Morin FC, Stenmark KR. Persistent pulmonary hypertension of the newborn. Am J Respir Crit Care Med 1995;151:2010.

3. Chang HK. Mechanisms of gas transport during ventilation by high frequency oscillation. J Appl Physiol 1984;56:553-63.

4. Kolton M, McGhee I, Bryan AC. Tidal volumes required to maintain isocapnia at frequencies from 3 to $30 \mathrm{~Hz}$ in the dog. Anesth Analg 1987;66:523-8.

5. Bryan AC, Slutsky A. Lung volume during HFO. Am Rev Respir Dis 1986;133:928-30.

6. Kolton M, Cattran CB, Kent G, Volgycsi G, Froese A, Bryan AC. Oxygenation during high frequency ventilation compared with conventional mechanical ventilation in two models of lung injury. Anesth Analg 1995;61:323-32.

7. Gerstmann DR, Fouke JM, Winter DC, Taylor AF, deLemos RR. Proximal, tracheal and alveolar pressures during high frequency oscillatory ventilation in a normal rabbit model. Pediatr Res 1990;28:367-73. pressure loss down the endotracheal tube and airways is also very large (unlike in conventional mechanical ventilation) and the alveolar pressures on HFO are trivial (7). It is essential that the volume recruitment manoeuvres be repeated whenever the oscillator is disconnected.

\section{LUNG INJURY}

The above strategy is extraordinarily effective in minimizing lung injury in the laboratory. It has been shown to reduce neutrophil sequestration and the production of inflammatory mediators, and to preserve surfactant function $(8,9)$. Histologically, HFO produces very little epithelial damage and scanty hyaline membrane formation. However, there is one major caveat: epithelial injury from mechanical ventilation in surfactant-deficient newborn animals occurs very rapidly (10). In animal models after $4 \mathrm{~h}$ of mechanical ventilation there is severe lung injury, and it is very difficult to recruit lung volume with HFO (11). This has been a major problem in many of the reported clinical trials for one reason or another; HFO is usually used after many hours of conventional mechanical ventilation when such damage may have occurred.

\section{CURRENT STATUS OF HFO}

The alarm and despondency created by the National Institutes of Health-sponsored HIFI Trial have now subsided (12). A number of large scale trials of HFO in preterm infants with respiratory distress syndrome in Europe, Japan and the United States have shown generally good results and no untoward side effects. It has been shown to reduce substantially the need for extracorporeal membrane oxygenation in pediatric respiratory failure from a variety of causes (13). The available oscillators all have small displacement pumps, but larger ones are appearing and the adult oscillators are in the prototype stage. Despite this, the good results are not as good as the animal data would lead us to expect. In part this may be due to delays in starting HFO, or to inadequate lung recruitment protocols to improve the ventilation of poorly ventilated areas of the lung. It is probably also due to the difference between the simplicity of animal models and the complexity of human disease.

8. Froese A, McCulloch P, Sugiwara M, Vaclavik S, Posmayer F, Moller F. Optimizing alveolar expansion prolongs the effectiveness of exogenous surfactant therapy in the adult rabbit. Am Rev Respir Dis 1993;148:569-77.

9. Imi Y, Kawano T, Miyasaka K, Tokata M, Toshimichi I, Okuyama K. Inflammatory chemical mediators during conventional mechanical ventilation and during high frequency oscillatory ventilation. Am J Respir Crit Care Med 1994;150:1550-4.

10. Nilsson R, Grossmann G, Robertson B. Lung surfactant and the pathogenesis of neonatal bronchiolar lesions induced by artificial ventilation. Pediatr Res 1978;12:249-55.

11. Suzuld H, Papazoglou K, Bryan AC. Relationship between $\mathrm{PaO}_{2}$ and lung volume during high frequency oscillatory ventilation. Acta Pediatr Jpn 1992;34:494-500.

12. HIFI Study Group. High frequency oscillatory ventilation compared with conventional mechanical ventilation in the treatment of respiratory failure in preterm infants. N Engl J Med 1989;320:88-93.

13. Paranka M, Clark R, Yoder B, Null D. Predictors of failure of high frequency oscillatory ventilation in term infants with severe respiratory failure. Pedatrics 1995;95:400-4. 


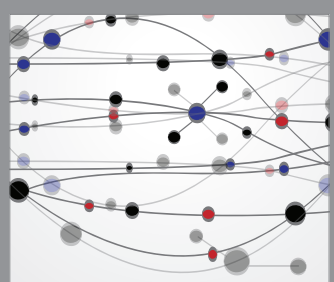

The Scientific World Journal
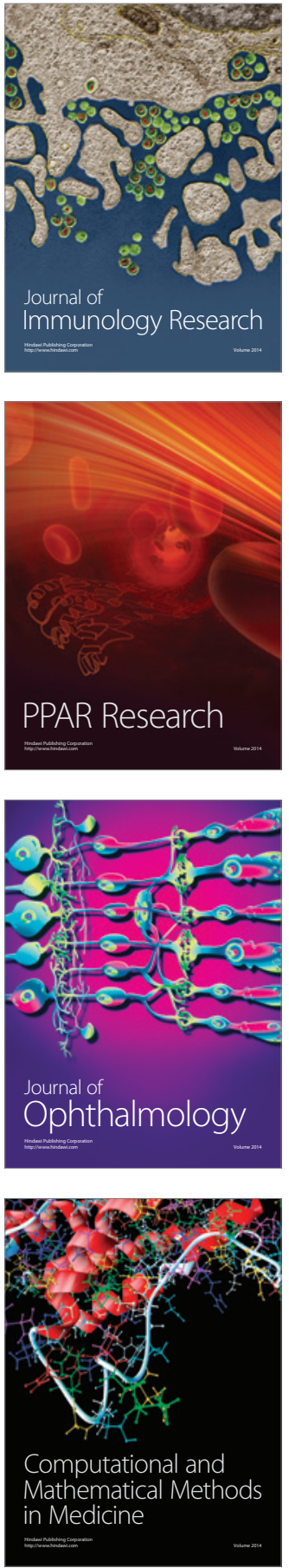

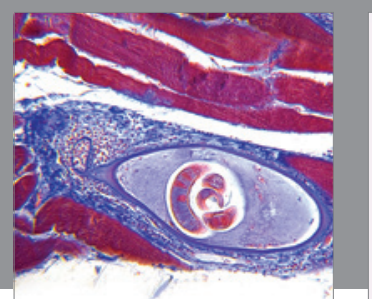

Gastroenterology Research and Practice

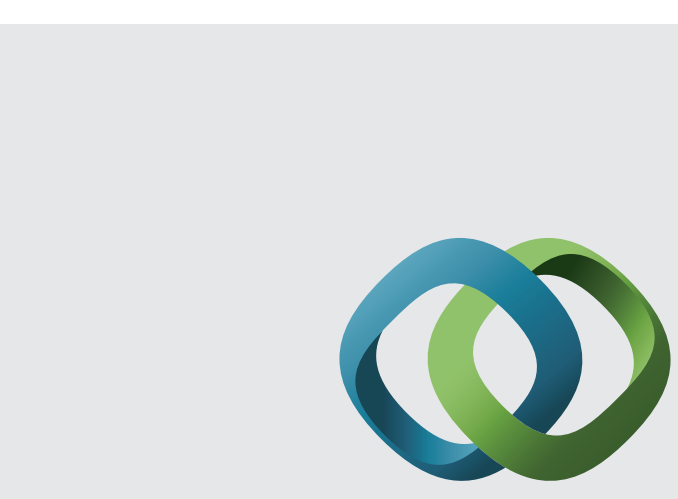

\section{Hindawi}

Submit your manuscripts at

http://www.hindawi.com
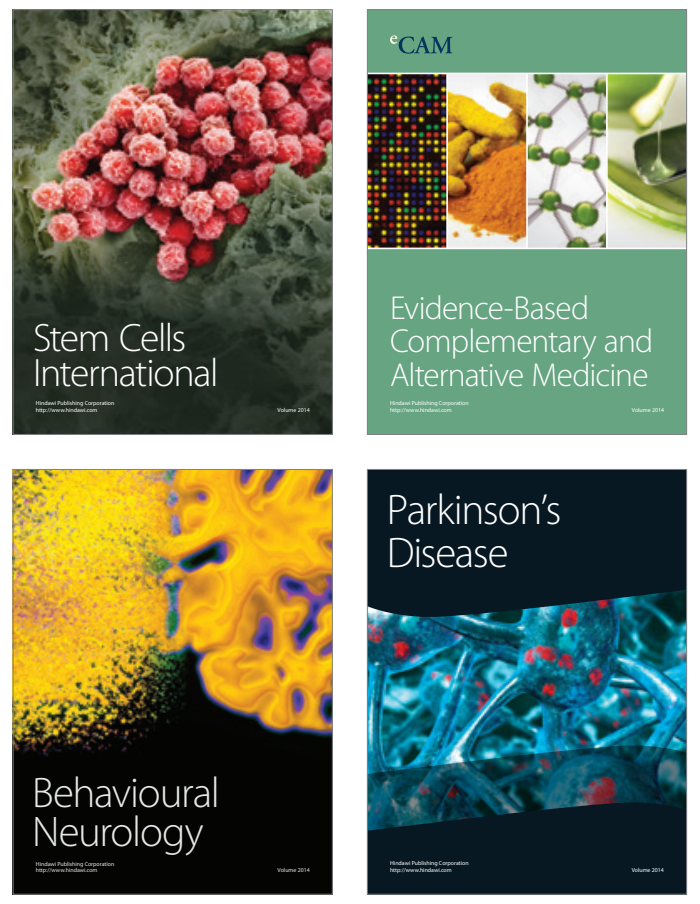
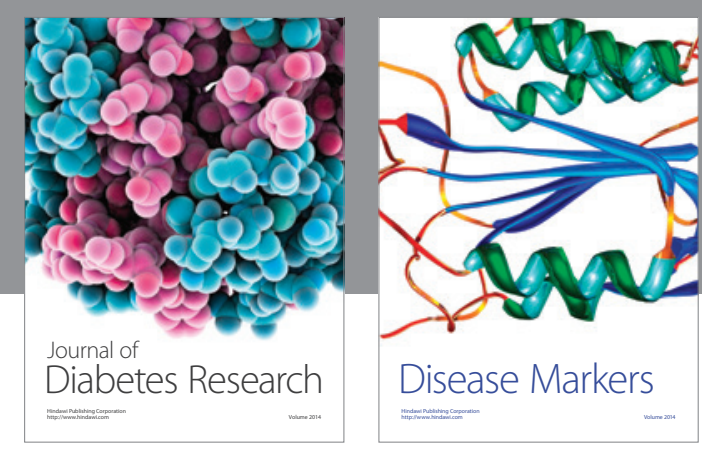

Disease Markers
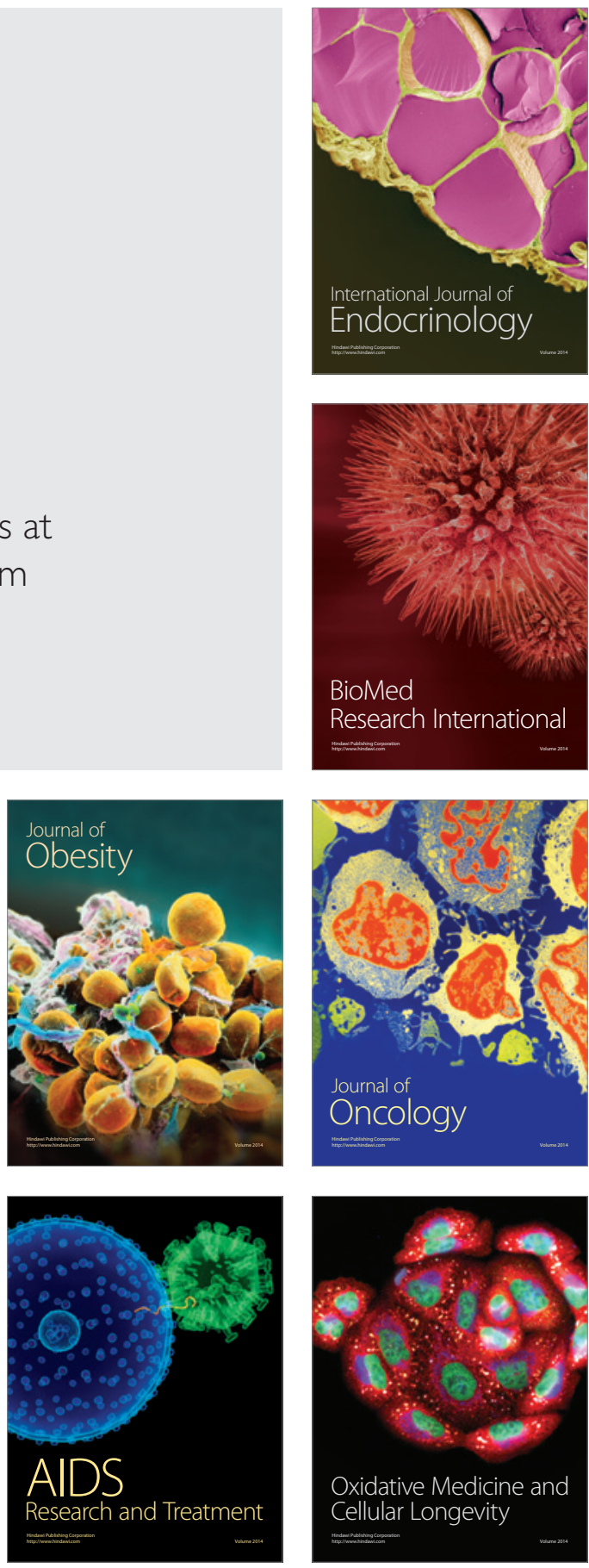